\title{
Decisive Analysis of Smoking and Periodontal Syndrome at Selected Dental Clinics, Saudi Arabia
}

\author{
Dr. Alhassan Khalid Alasiari ${ }^{1}$, Dr. Abrar Abdulrazaq Makhdom ${ }^{2}$ \\ ${ }^{1}$ General Dentist, Dental Speciality Center -King Fahad Hospital, Almadina, KSA \\ ${ }^{2}$ General Dentist, Ministry of Health, KSA
}

\begin{abstract}
Background: Cigarette smoking is one of the most preventable sources of morbidity and premature death worldwide. In the United States, smoking is responsible for approximately one in five deaths smoking has been shown to significantly increase the risk of tooth loss from periodontal disease. The effect appears to be dose-related, with heavy smokers exhibiting a significantly greater risk of tooth loss from periodontal disease compared to nonsmokers and lighter smokers. These patients have levels of risk similar to those of non-smokers. The aim of this provide decisive analysis which will consequently, will assist to provide some evidence support for the contribution between smoking and periodontal syndrome. Objective: The aim of this provides a decisive analysis to provide some evidence support for the contribution between smoking and periodontal syndrome. At the selected dental clinics, Saudi Arabia. Method: Structured survey was conducted at ten dental clinics, Saudi Arabia to provide a decisive analysis to provide some evidence support for the contribution between smoking and periodontal syndrome at the selected dental clinics, Saudi Arabia. Results: Several studies have shown that the effect of smoking on periodontal tissues may involve both of these processes. For example, smokers tend to have depressed numbers of T-helper lymphocytes, which are important cells of the immune system to regulate cell-mediated immunity and the activity of B lymphocytes. To boot, the host requires functional neutrophils to deal effectively with bacterial infections. Tobacco smoke has been shown by several studies to have a deleterious effect on various neutrophil functions. Conclusions: The existing research findings discovered that there was strong evidences replicate for the correlation between smoking and periodontal syndrome within the study setting.
\end{abstract}

Keywords: Decisive Analysis; Awareness; \&Periodontal Syndrome

\section{Introduction}

Typically, the diseased tissues of smokers tend to have a firmer appearance and less bleeding compared to that of nonsmokers. The term disease masking is used because the vaso-constrictive properties of tobacco smoke hide the inflammatory and destructive changes occurring within the periodontium. (Hennemeyer, 2013).

The periodontal tissues are compromised by the initial vasoconstriction, resulting in decreased blood flow to the gingiva. This masks the normal early signs of periodontal problems by decreasing gingival inflammation, erythematic, and bleeding despite the presence of the disease. The record of diseases origin by smoking has been expanded to include abdominal aortic aneurysm, acute myeloid leukemia, cataract, cervical cancer, kidney cancer, pancreatic cancer, pneumonia, periodontitis, and stomach cancer. These are in addition to diseases previously known to be caused by smoking, including bladder, esophageal, laryngeal, lung, oral, and throat cancers, chronic lung diseases, coronary heart and cardiovascular diseases, as well as reproductive effects and sudden infant death syndrome. (Haber,2003).

Preceding epidemiological results showed that smoking is a significant risk factor for the development of periodontal syndrome.5-7 Smokers have 2.5 to 3.5 times greater risk of severe periodontal attachment loss.8 Risk calculations suggested that 40 per cent of chronic periodontitis cases may be attributed to smoking, with an increased odds ratio of 5.4 for chronic periodontitis in smokers, (Wright,et al., (1993).
According to Bergstrom \& Floderus , (2002), smokers nearby another way when compared with non-smokers. Smokers have deeper probing depths, more deep pockets and more attachment loss, including more gingival recession. Smokers also have more alveolar bone loss and more teeth with function involvement. Smokers also tend to have a higher level of tooth loss than non-smokers after adjusting for oral hygiene, age, gender, and socio-economic level. The effect of smoking on the periodontal tissues is dosedependent. Both daily consumption quantity and duration of smoking are related. Smokers have a higher prevalence of acute necrotizing ulcerative gingivitis.

\section{Participants and Methods}

This study was conducted in April, 2016 among periodontal staff at the dental clinics, Saudi Arabia. The study was granted ethical approval by the clinics ethical committee.

The participants were selected from the selected dental clinics. After signing an informed written consent form, the questionnaire was given to each participant. Before administration of the questionnaire, the purpose of the study was explained to each respondent and confidentiality of the information guaranteed.

A cross-sectional survey was conducted at ten dental clinics, Saudi Arabia. Review is to judge the evidence for the involvement between smoking and periodontal syndrome at the selected dental clinics, Saudi Arabia. 


\section{International Journal of Science and Research (IJSR) \\ ISSN (Online): 2319-7064}

Index Copernicus Value (2013): 6.14 | Impact Factor (2015): 6.391

\section{Results}

Whether it is direct heat from the cigarette, the vasoactive response from nicotine, or a change in the host response to periodontal pathogens, the mechanism by which smoking induces periodontal attachment loss is currently unknown. Smoking has not only been shown to increase the severity of periodontal disease, but also to decrease the response of the gingival tissues to periodontal therapy, resulting in a greater incidence of refractory disease. Obviously, there is a plethora of published information correlating periodontal syndrometo both tooth loss and systemic manifestations. These systemic manifestations include increased risk of coronary artery disease; diabetes; osteopenia; and premature, low-birth-weight babies. Further, it has been demonstrated in numerous studies that smoking cessation leads to improved periodontal health and improved response to periodontal therapy, thus improving overall health. Therefore, it would greatly benefit our patients if we, as dental professionals, made a deliberate effort to promote smoking-cessation programs as well as educate our community on the benefits of not smoking.

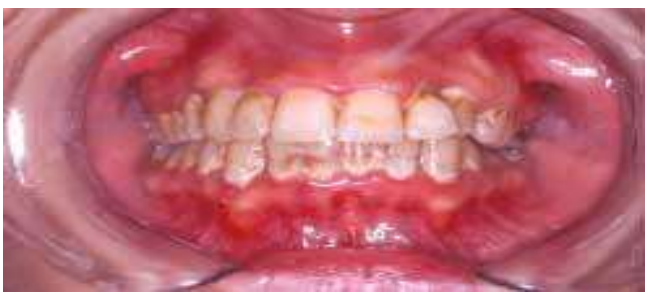

Figure 1: Acute necrotizing ulcerative gingivitis with severe caries.
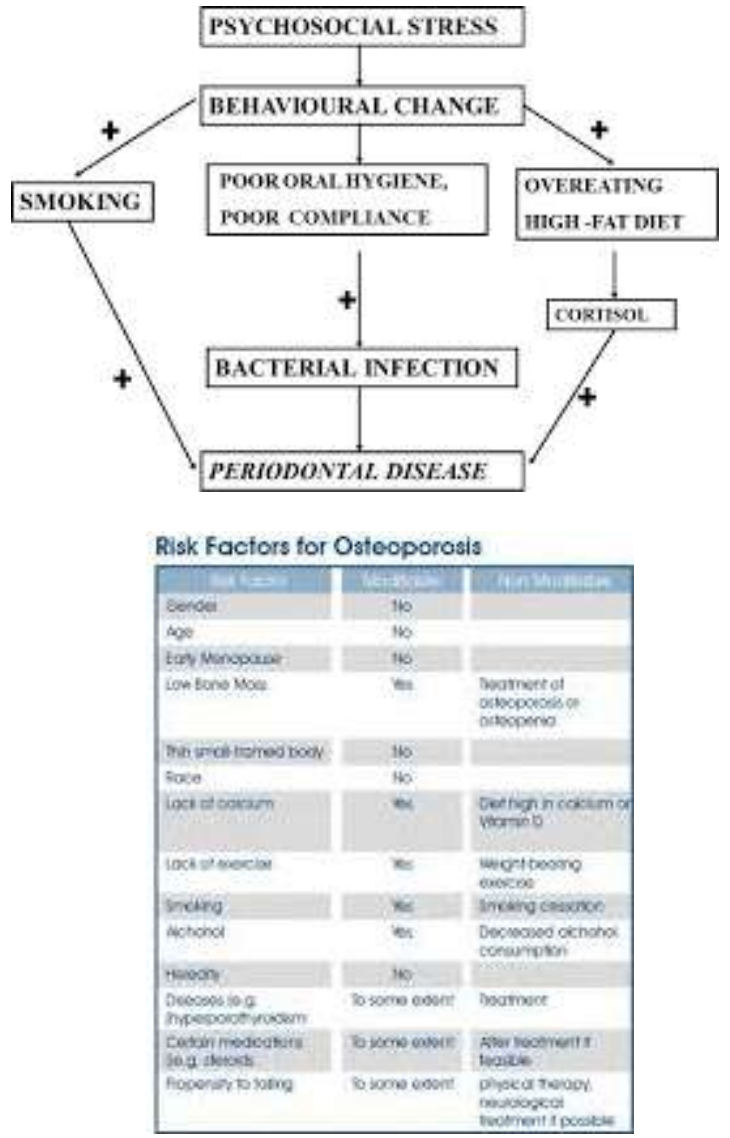

\section{Discussion}

Whether it is direct heat from the cigarette, the vasoactive response from nicotine, or a change in the host response to periodontal pathogens, the mechanism by which smoking induces periodontal attachment loss is currently unknown. Smoking has not only been shown to increase the severity of periodontal disease, but also to decrease the response of the gingival tissues to periodontal therapy, resulting in a greater incidence of refractory disease.

Obviously, there is a plethora of published information correlating periodontal diseases to both tooth loss and systemic manifestations. These systemic manifestations include increased risk of coronary artery disease; diabetes; osteopenia; and premature, low-birth-weight babies. Further, it has been demonstrated in numerous studies that smoking cessation leads to improved periodontal health and improved response to periodontal therapy, thus improving overall health.

Therefore, it would greatly benefit our patients if we, as dental professionals, made a deliberate effort to promote smoking-cessation programs as well as educate our community on the benefits

Tobacco use has been implicated as a risk factor for alveolar bone loss. One hypothesis has been the possible stimulant effect of nicotine on osteoclastic activity, the cells most responsible for bone resorption. A study of porcine bone marrow cells found that nicotine is nontoxic to osteoclasts at clinically relevant levels, and appears to stimulate osteoclast differentiation and the resorption of calcium phosphate, the major inorganic component of bone. It is thought that nicotine-modulated osteoclast stimulation may partially explain the increased rapidity of alveolar bone loss and refractory disease incidence in smokers.

Approximately $90 \%$ of patients who were categorized as having failed to respond to conventional therapy were smokers (MacFarlane et al., 1992; Wolff et al., 1994). Recent work by Colombo et 1. (1998) has disagreed with this stated proportion, since these investigators found that only 25 , of their patients were current smokers, but that $40 \%$, were former smokers.

Bostrom et al. (1 998) suggested that former smokers often begin smoking again, and therefore one must interpret the status of the former smokers cautiously, since self-reporting of smoking status is not reliable (Gonzalez et al., 996). Even though smokers will also benefit from treatment, albeit to a lesser degree, treatment failures tend to predominate among smokers.

Kinane and Radvar (1997) found that the response to nonsurgical mechanical therapy is particularly poor in deep pockets in smokers. Although the attachment gain was also greater among the non-smokers than the smokers, this was not significant. 


\section{International Journal of Science and Research (IJSR) \\ ISSN (Online): 2319-7064}

Index Copernicus Value (2013): 6.14 | Impact Factor (2015): 6.391

This indicates that, after treatment, a greater degree of recession occurred among the non-smokers compared with the smokers. In the description of the appearance of smokers' periodontal condition, and in studies looking crosssectional at smokers, a frequently noted feature is the level of recession, which is often noted as worse in smokers than in non-smokers (Martinez-Canutt et a., 1995; Gunsolley et al., 1998).

A recent study in Australia using the National Survey of Adult Oral Health 2004-2006 to investigate the smokingperiodontitis relationship reported that former and current smokers had significantly higher periodontitis prevalence than never-smokers..$^{\mathbf{1 9}}$ It was estimated that the population attributable fraction of smoking (classified as both current and former smokers) was 32 per cent for moderate to severe periodontitis (equivalent to 700000 cases).

\section{Conclusions}

The current study results revealed that there was strong evidences reflect for the contribution between smoking and periodontal syndrome within the study setting. Data available to date seem to suggest that smoking exerts a chronic effect by impairing the vasculature of the periodontal tissues rather than a simple vasoconstrictive effect. The suppressed vasculature has contributed to less gingival redness, less bleeding on probing and may also lead to an impaired healing response by affecting the revascularization.

\section{Acknowledgements}

Appreciation is hereby extended all the staff cooperates with the current research .

\section{References}

[1] Hennemeyer CL, Scales DK, Hokett SD, Cuenin MF, Peacock ME, Parker MH, Brewer PD, Chuang AH. Nicotine stimulates osteoclast resorption in a porcine marrow cell model. J Periodontol 2013; 74:1440-1446.

[2] Haber J, Wattles J, Crowley M, Mandell R, Joshipura K, Kent RL. Evidence for cigarette smoking as a major risk factor for periodontitis. J Periodontol 2003; 64:16-23.

[3] Wright SC, Zhong J, Zheng H, Sarrick JW. Nicotine inhibition of apoptosis suggests a role in tumor promotion. FASEB 1993; 7:1045-1051.

[4] Bergstrom J, Floderus-Myrhed B. Co-twin control study of the relationship between smoking and some periodontal disease factors. Community Dent Oral Epidemiol , 2002 ; 11:113-116.

[5] Beck ID Cusmano L, Green-Helms W, Koch GG, Offenbacher S (1997). A 5-year study of attachment loss in community-dwelling older adults: incidence density. Periodont Res 32: 506-

[6] Bergstrcim (1989). Cigarette smoking as risk factor in ,hroni cperiodontal disease. Comniunity Dent Orol Epidemiol 17 245-247.

[7] Bergstrom Ii 1990). Oral hygiene compliance and gingivitis expressi $\mathrm{n}$ in cigarette smokers. Scand I Dent Res 98:497-5Q3 Bergstr6m1m Eliasson S, Preber H
(1991). Cigarette smoking and eriodontal bone loss. I Periodontol 62:242-246.

[8] Bernzweig Ef Payne JB, Reinhardt RA, Dyer 1K, Patil KD 1998). Nicotine and smokeless tobacco effects on ging val an( peripheral blood -nononuclear cells. Clin Pertioloitol 25:246-252.

[9] Bolin A 1986. Proximal alveolar bone loss in a longitudiinal radiop_graphic investigation. Swed Dent 35(Supp 1- 1-08.

[10]Bolin A Eklund G Frithiof L Lavstedt S (1993). The effect of changed smoking habits on marginal alveolar bone loss, A iongitudinal study. Swed Dent 1 17:211216.

[11] Bostrom L. inder LE, Bergstrom I (1998a). Influence of smoking oni the outcome of periodontal surgery. A 5vear follow-up. Clin Periodontol 25:194-201.

[12] Bostrorm Linder LE, Bergstrorr (1998b). Clinical expressivr of TNF-alpha in smoking-associated periodontai disease. I Clin Periodontol 25:767-773.

[13] Clarke NG Shephard BC, Hirsch RS (1981). The effect of intra-arterial epinephrine and nicotine on gingival circulation. Oril Surq Oral Med Oral Pathol 52:577-582.

[14] Colombo AP Ettirmiadi C, Haffajee AD, Cugini MA, Socransky SS (1998). Serum IgG2 level, Gm(23) allotype and FcgammaRlla and FcgammaRlllb receptors in refractory periodontal disease. Clin Perodontol 25:465-474

[15] Cortellini P, Paolo G, Prato P, Tonetti MS 1996). Longterm stability of clinical attachment following guided tissue regeneration and conventional therapy. Clin Periodontol 23:106-11 1 .

[16] Croucher R, Marcenes WS, Torre MC, Hughes F, Sheiham A (1997). The relationship between life-events and periodontitis. A case-control study. Clin Peiodontol 24:39-43.

[17]Danielsen B, Manji F, Nagelkerke N, Fejerskov 0, Baelum V ( 1990). Effect of cigarette smoking on the transition dynamics in experimental gingivitis. Clincal Periodontol 17:159-164.

[18] Dolan TA, Gilbert GH, Ringelberg ML, Legler DW, Antonson DE, Foerster U, et 1. (1997). Behavioural risk indicators of attachment loss in adult Floridians. J Clinical Periodontol 24:223-232.

[19] Ferson MA, Edwards A, Lind GW, Milton GW, Hersey $P$ (1979). Low natural killer-cell activity and immunoglobulin levels associated with smoking in human subjects. Int I Cancer 23:603-609. Genco RI (1992). Host responses in periodontal syndrome: current concepts. I Periodontol 63:338-355.

[20] Gonzalez YM, De Nardin A, Grossi SG, Machtei EE, Genco RI, De Nardin E (1996). Serum cotinine levels, smoking, and periodontal attachment loss. J Dent Res 75:796-802.

[21] Grossi SG, Zambon II, Ho AW, Koch G, Dunford RG, Machtei EE, et al. (I1994). Assessment of risk for periodontal disease.. Risk indicators for attachment loss. J Periodontol 65:260-267.

[22] Tangada SD, Califano IV, Nakashima K, Quinn SM, Zhang J-B, Gunsolley IC, et al. (1997). The effect of smoking on serum IgG2 reactive with Actinobacillus actinomycetemcomitans in early-onset periodontitis patients. Periodontol 68:842-850.

\section{Volume 6 Issue 12, December 2017}

